\title{
Perancangan Question Answering System E-Marketplace Sigertengah Menggunakan Metode Scrumban (Studi Kasus: Kelompok Pedagang Sigertengah)
}

\author{
Caca Arif Herdian ${ }^{1}$ \\ ${ }^{1}$ Sekolah Tinggi Manajemen Informatika dan Komputer LIKMI; Jl. Ir. H. Juanda No. 96 \\ Bandung, Telepon +62-22-250-2121 Fax +62-22-250-5151 \\ ${ }^{3}$ Pascasarjana Magister Sistem Informasi, STMIK LIKMI, Bandung \\ e-mail: cacaarifherdian@gmail.com
}

\begin{abstract}
Abstrak
Kegiatan penjualan telah dilakukan manusia sejak awal peradaban, seiring perkembangan zaman, cara yang dilakukan senantiasa berubah. Bentuk kegiatan penjualan saat ini berkembang yaitu dengan menggunakan media elektronik yang disebut E-Commerce dan semakin berkembang menjadi E-Marketplace. Persaingan antar E-Marketplace semakin kompetitif dengan berbagai macam pelayanan terbaik untuk memuaskan penggunanya. Tuntutan pelayanan prima kepada konsumen saat ini menjadikan Usaha Mikro Kecil dan Menengah (UMKM) harus mengikuti perkembangan sistem informasi dan teknologi informasi. Kelompok pedagang Sigertengah sebagai sebuah organisasi di bidang UMKM yang menjual benda seni tentunya dituntut untuk memberikan pelayanan prima dalam pengelolaan jual beli benda seni. Saat ini sistem informasi yang telah dibangun dengan berbasis E-Marketplace masih dalam tahap pengembangan. Informasi terkait dengan benda seni yang ditawarkan di EMarketplace Sigertengah belum memuat informasi tentang keaslian atau orisinalitas benda seni tersebut. Dalam penelitian ini akan dibahas mengenai bagaimana merancang sebuah Question Answering System menggunakan metode Scrumban dan Unified Modeling Language untuk menggambarkan rancangan sistem. Hasil penelitian ini yaitu rancangan model dari Question Answering System E-Marketplace yang terdiri dari dari beberapa aspek diantaranya aspek Pengguna, aspek perangkat lunak, aspek perangkat keras dan aspek skema jaringan internet rencana implementasi sistem.
\end{abstract}

Kata kunci: E-Marketplace, Question Answering System, Scrumban, Unified Modeling Language

\begin{abstract}
Sales activities have been carried out by humans since the beginning of civilization, along with the times, the way they are done is always changing. Form of sales activity is currently developing, namely by using electronic media called E-Commerce and increasingly developing into E-Marketplace. The competition between E-Marketplace is increasingly competitive with various kinds of the best services to satisfy users. The current demand for excellent service to consumers means that Usaha Mikro Kecil dan Menegah (UMKM) must follow developments in information systems and information technology. Sigertengah traders group as an organization in the field of UMKM that sells art objects is certainly required to provide excellent service in managing the buying and selling of art objects. Currently, the information system that has been built based on E-Marketplace is still in the development stage. Information related to art objects offered on the Sigertengah E-Marketplace does not include information about the authenticity or originality of these art objects. This research will discuss
\end{abstract}


about how to design of Question Answering System using Scrumban method and Unified Modeling Language to describe the system design. The result of this research is a model design of Question Answering System E-Marketplace which consists of several aspects including user aspects, software aspects, hardware aspects and internet network scheme aspects of system implementation plans.

Keywords: E-Marketplace, Question Answering System, Scrumban, Unified Modeling Language

\section{PENDAHULUAN}

Kegiatan penjualan telah dilakukan manusia sejak awal peradaban. Seiring berkembangnya manusia, cara maupun sarana yang digunakan untuk berjualan senantiasa berubah. Bentuk dari penjualan yang semakin memudahkan penggunanya saat ini adalah EEommerce atau penjualan online. E-Commerce ini merupakan penerapan E-Business terkait transaksi komersial seperti transfer dana elektronik, pemasaran elektronik (E-Marketing), pemrosesan transaksi online (Online Transaction Processing) serta pertukaran data elektronik (Electronic Data Interchange/EDI). Secara umum dapat didefinisikan sebagai bentuk transaksi jual beli barang atau jasa dengan menggunakan media elektronik. Jenis E-Commerce yang sekarang berkembang adalah E-Marketplace. Hal ini tentu saja menjadikan transaksi lebih aman dengan adanya penengah. Maka saat ini persaingan antar E-Marketplace semakin kompetitif dengan berbagai macam pelayanan terbaik untuk memuaskan penggunanya [1]. Tuntutan pelayanan prima kepada konsumen saat ini menjadikan Usaha Mikro Kecil dan Menengah (UMKM) harus mengikuti perkembangan sistem informasi dan teknologi informasi yang mensyaratkan partisipasi, orientasi pada akuntabilitas, transparansi, responsif, efektif dan efisien, maka pemenuhan kebutuhan terhadap data dan informasi dalam fungsi bisnis yang dijalankan suatu organisasi menjadi sangat penting. Hal ini mendorong untuk dikembangkannya sistem informasi didalam organisasi [2]. Kelompok pedagang Sigertengah sebagai sebuah organisasi di bidang UMKM dituntut untuk memberikan pelayanan prima dalam pengelolaan jual beli benda seni. Sistem informasi yang telah dibangun dengan berbasis E-Marketplace masih dalam tahap pengembangan. Informasi terkait dengan benda seni yang terdapat pada $E$ Marketplace Sigertengah belum memuat informasi tentang keaslian atau orisinalitas benda seni tersebut. Untuk mempermudah pencarian dan meningkatkan proses didalam proses pencarian terkait benda seni diperlukan sebuah sistem untuk menghasilkan informasi tersebut.

Question Answering System merupakan sistem untuk penggunanya dapat menyatakan pertanyaan dalam bentuk spesifik serta alami terkait benda-benda seni yang ditawarkan pada $E$ Marketplace Sigertengah ditambah dengan menggunakan pattern matching untuk menemukan informasi hasil dari pencocokkan antara pertanyaan dan jawaban dimana hal tersebut akan sangat membantu calon pembeli dalam mengeksplorasi benda seni. Pentingnya pengembangan sebuah sistem informasi dalam organisasi sebagai pemberi layanan atau pelaksana, maka perlu adanya pengembangan sistem informasi secara spesifik dalam hal eksplorasi benda seni yang akan dibeli [3], [4]. Dalam mengembangkan Question Answering System ini dibutuhkan sebuah metode yang memiliki kemampuan untuk menyesuaikan secara cepat dalam arti dinamis maka dalam penelitian dipilih metode Agile Scrumban karena dalam metode ini dapat menggabungkan antara Scrum dan Kanban dimana Scrum fokus terhadap aliran dan waktu penyelesaian pekerjaan dengan memprioritaskan pekerjaan yang harus dikerjaan, sedangkan Kanban memvisualisasikan jumlah pekerjaan yang telah dan belum diselesaikan sehingga dapat

Herdian, [Perancangan Question Answering System E-Marketplace Sigertengah Menggunakan Metode Scrumban (Studi Kasus: Kelompok Pedagang Sigertengah)] 
mewujudkan pengelolaan E-Marketplace Benda Seni dengan pelayanan prima terhadap konsumen yang memberikan informasi terkait benda seni [5],[6],[7],[8],[9].

\section{METODE PENELITIAN}

Metode yang digunakan dalam penilitian ini menggunakan metode Scrumban [10]. Dimana Scrumban merupakan kombinasi antara Scrum dan Kanban yang menjadikan model pengembangan perangkat lunak [11]. Didalam Scrumban juga tim pengembang dan stakeholder dapat beradaptasi untuk memenuhi kebutuhan pada saat proses proses produksi tanpa terbebani oleh metodologi proyek. Scrumban mewarisi dari konsep Kanban dimana dapat melakukan penghapusan elemen yang mungkin menghasilkan sesuatu yang tidak diharapkan, sehingga meminimalisir proses yang tidak dibutuhkan. Scrumban juga dapat mengoptimalkan dari upaya tim dalam mencapai standar kualitas yang direncanakan dan diasumsikan Tahapan dari penilitan ini dapat dilihat pada Gambar 1.

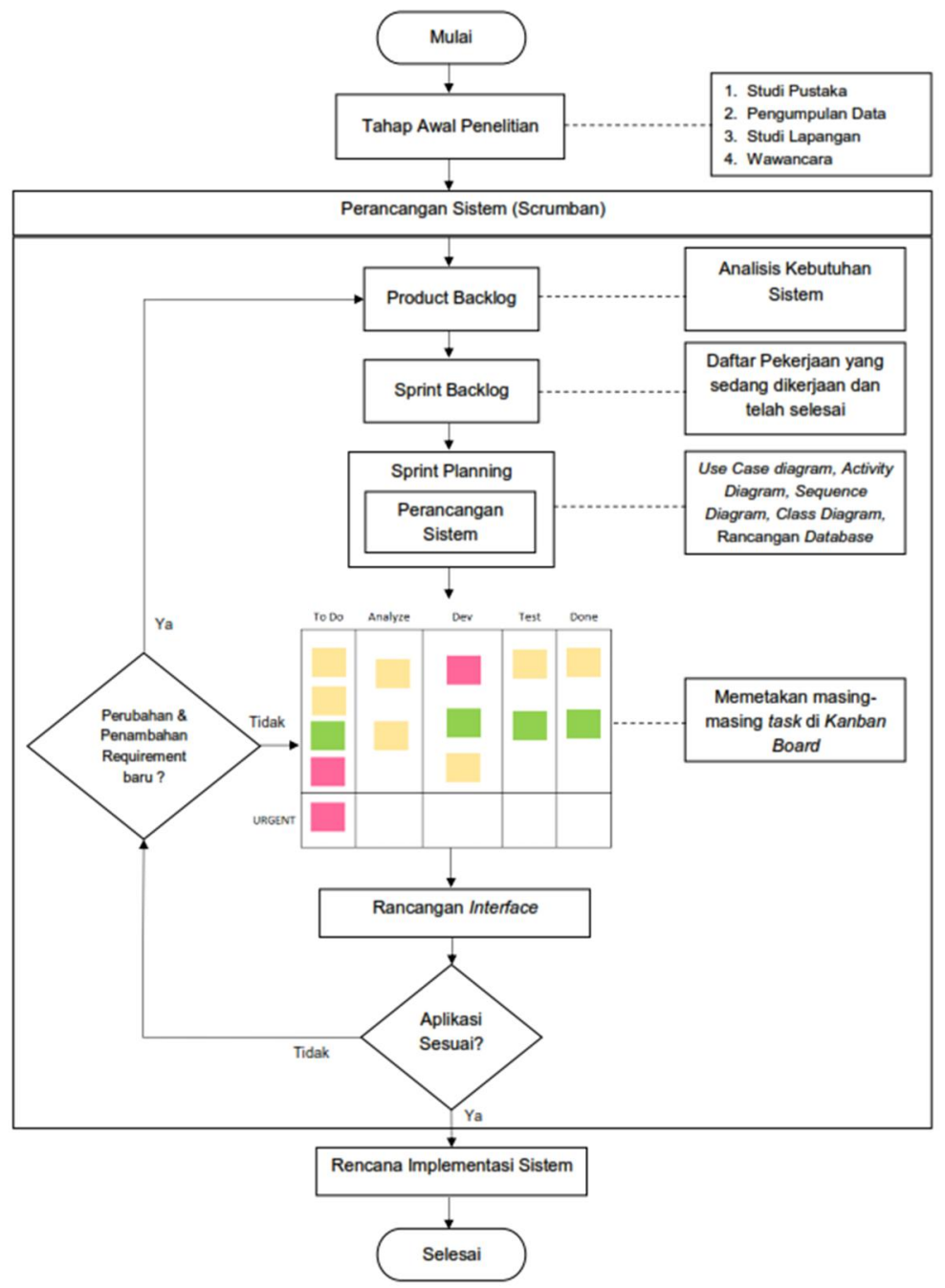

Gambar 1. Tahapan Penelitian

Herdian, [Perancangan Question Answering System E-Marketplace Sigertengah Menggunakan Metode Scrumban (Studi Kasus: Kelompok Pedagang Sigertengah)] 
Adapun uraian dari masing-masing tahapan penelitian meliputi:

\subsection{Tahapan Awal Penelitian}

Dalam tahap ini dilakukan beberapa aktivitas diantaranya mempelajari latar belakang permasalahan, memnentukan rumusan masalah, menentukan tujuan penelitian, menentukan ruang lingkup, studi pustaka dan wawaancara.

\subsection{Perancangan Sistem Menggunakan Scrumban}

Adapun aktivitas dalam perancangan sistem menggunakan metode Scrumban adalah sebagai berikut:

a. Product Backlog

Product Backlog menerima input dari tahapan pertama, pada tahapan Product Backlog ini menguraikan kebutuhan-kebutuhan dari Question Answering System E-Marketplace

Sigertengah. Adapun yang menjadi output dari Product Backlog dapat dilihat pada Tabel 1.

Tabel 1. Product Backlog Question Answering System E-Marketplace Sigertengah

\begin{tabular}{|c|l|}
\hline No & \multicolumn{1}{|c|}{ Product Backlog } \\
\hline 1 & $\begin{array}{l}\text { Rancangan Use Case Diagram Question Answering System E-marketplace } \\
\text { Sigertengah }\end{array}$ \\
\hline 2 & Rancangan Activity Diagram Question Answering System E-marketplace Sigertengah \\
\hline 3 & Rancangan Class Diagram Question Answering System E-marketplace Sigertengah \\
\hline 4 & $\begin{array}{l}\text { Rancangan Sequence Diagram Question Answering System E-marketplace } \\
\text { Sigertengah }\end{array}$ \\
\hline 5 & Rancangan Database Question Answering System E-marketplace Sigertengah \\
\hline 6 & Rancangan Interface Question Answering System E-marketplace Sigertengah \\
\hline
\end{tabular}

b. Sprint Backlog

Pada tahapan ini menguraikan tujuan dari masing-masing pekerjaan, apa yang harus dilakukan, sedang dikerjaan, dan sudah diselesaikan. Adapun output dari Sprint Backlog yaitu daftar pekerjaan yang dapat dilihat pada Tabel 2 .

Tabel 2. Sprint Backlog Question Answering System E-Marketplace Sigertengah

\begin{tabular}{|c|c|c|c|c|}
\hline \multicolumn{5}{|c|}{ Sprint Backlog } \\
\hline No & Forecast & To Do & In Progress & Done \\
\hline 1 & Use Case Diagram & $\begin{array}{l}\text { Rancangan Use Case Diagram } \\
\text { Question Answering System } \\
\text { E-marketplace Sigertengah }\end{array}$ & & \\
\hline 2 & Activity Diagram & $\begin{array}{l}\text { Rancangan Activity Diagram } \\
\text { Question Answering System } \\
\text { E-marketplace Sigertengah }\end{array}$ & & \\
\hline 3 & Class Diagram & $\begin{array}{l}\text { Rancangan Class Diagram Question } \\
\text { Answering System } \\
\text { E-marketplace Sigertengah }\end{array}$ & & \\
\hline 4 & Sequence Diagram & $\begin{array}{l}\text { Rancangan Sequence Diagram } \\
\text { Question Answering System } \\
\text { E-marketplace Sigertengah }\end{array}$ & & \\
\hline 5 & Database & Rancangan Database & & \\
\hline
\end{tabular}

Herdian, [Perancangan Question Answering System E-Marketplace Sigertengah Menggunakan Metode Scrumban (Studi Kasus: Kelompok Pedagang Sigertengah)] 


\begin{tabular}{|c|c|c|c|c|}
\hline \multicolumn{5}{|c|}{ Sprint Backlog } \\
\hline No & Forecast & To Do & In Progress & Done \\
\hline & & $\begin{array}{l}\text { Answering System } \\
\text { E-marketplace Sigertengah }\end{array}$ & & \\
\hline 6 & Interface & $\begin{array}{l}\text { Rancangan Interface Question } \\
\text { Answering System } \\
\text { E-marketplace Sigertengah }\end{array}$ & & \\
\hline
\end{tabular}

c. Sprint Planning

Pada tahapan ini menguraikan terkait desain dari Question Answering System EMarketplace Sigertengah. Adapun Sprint Planning yaitu rancangan sistem yang dibangun seperti rancangan Use Case Diagram, Activty Diagram, Sequence Diagram, Class Diagram, dan rancangan Database. Masing-masing rancangan tersebut menjadi sebuah Sprint yang digambarkan menggunakan Unified Modeling Language.

1. Sprint 1: Use Case Diagram

Dalam memodelkan hubungan antara Pengguna dan sistem, Use Case Diagram yang dirancang pada Question Answering System E-Marketplace Sigertengah terdapat beberapa Use Case : Use Case Login dimana extend dari Use Case Login yaitu Use Case Logout, Use Case Kelola Data Pertanyaan dimana extend dari Use Case ini diantaranya Tambah Data Pertanyaan, Lihat Data Pertanyaan, Edit Data Pertanyaan, dan Hapus Data Pertanyaan, Use Case Kelola Data Jawaban dimana extend dari Use Case ini diantaranya Tambah Data Jawaban, Lihat Data Jawaban, Edit Data Jawaban, dan Hapus Data Jawaban, Use Case Cari Jawaban. Adapun Use Case Diagram dari Question Answering System E-Markerplace Sigertengah dapat dilihat pada Gambar 2.

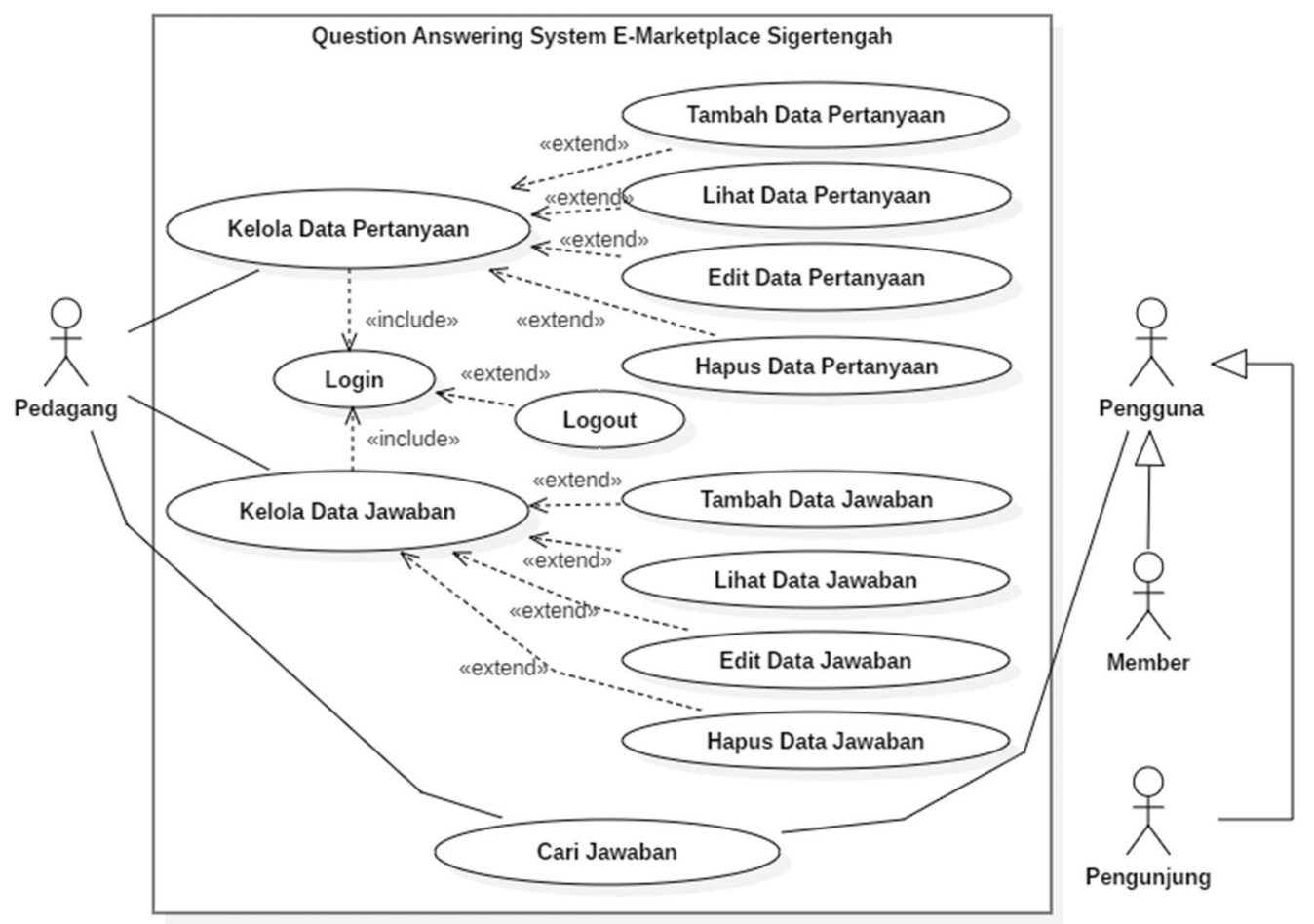

Gambar 2. Use Case Diagram Question Answering System E-Markertplace Sigertengah

Herdian, [Perancangan Question Answering System E-Marketplace Sigertengah Menggunakan Metode Scrumban (Studi Kasus: Kelompok Pedagang Sigertengah)] 


\section{Sprint 2: Activity Diagram}

Activity Diagram Cari Jawaban yaitu aktivitas yang merupakan proses untuk pengguna dapat mengetahui informasi terkait benda seni yang ditawarkan pada E-Marketplace Sigertengah yang akan sangat membantu calon Pembeli dalam mengeksplorasi benda seni agar dapat lebih meyakinkan dari segi orisinalitas dari benda seni tersebut. Activity Diagram Cari Jawaban dapat dilihat pada Gambar 3.

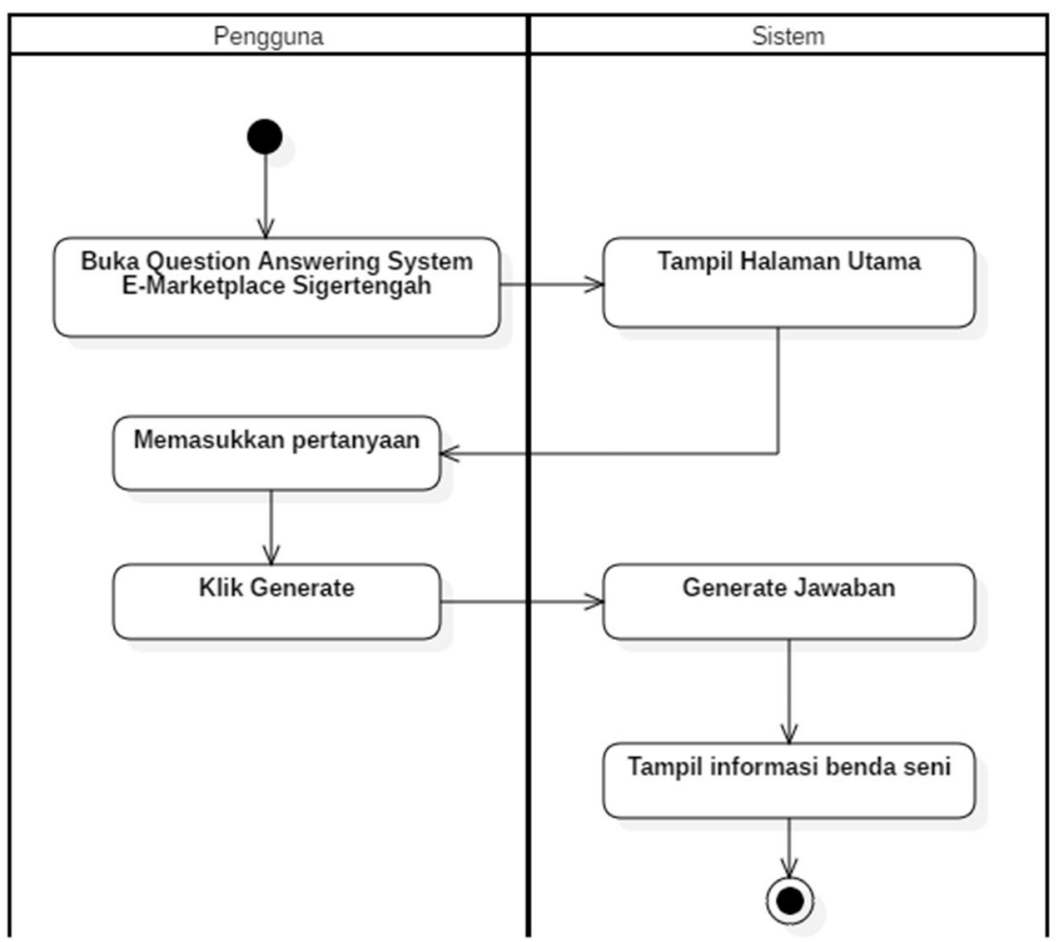

Gambar 3. Activity Diagram Cari Jawaban

3. Sprint 3: Class Diagram

Class Diagram ini menggambarkan terkait kelas dan relasi antar kelas. Adapun Class Diagram Question Answering System E-Marketplace Sigertengah ini menggunakan konsep Model, View dan Controller (MVC) dengan berfokus terhadap framework yang bertujuan untuk mempermudah dalam mengetahui bagian-bagian dari kelas seperti boundary (tampilan), control (perintah-perintah), serta entity (model atau database) yang dapat dilihat pada Gambar 4.

Herdian, [Perancangan Question Answering System E-Marketplace Sigertengah Menggunakan Metode Scrumban (Studi Kasus: Kelompok Pedagang Sigertengah)] 


\begin{tabular}{|c|c|c|}
\hline $\begin{array}{l}\text { «boundarys } \\
\text { V_Pertanyaan }\end{array}$ & $\begin{array}{l}\text { "controls } \\
\text { C_Pertanyaan }\end{array}$ & $\begin{array}{l}\text { «entity" } \\
\text { M_Pertanyaan }\end{array}$ \\
\hline \multirow{3}{*}{$\begin{array}{l}\text { +TampilanHalamanDataPertanyaan } 0 \\
\text { +Form TambahDataPertanyaan( } \\
\text { +FormEditDataPertanyaan } 0 \\
\text { +TampilanDataPertanyaan } 0 \\
\end{array}$} & \multirow{3}{*}{$\begin{array}{l}\text { +KelolaDataPertanyaan 0 } \\
\text { +TambahDataPertanyaan 0 } \\
\text { +EditDataPertanyaan0 } \\
\text { +LihatDataPertanyaan0 } \\
\text { +HapusDataPertanyaan } 0\end{array}$} & $\begin{array}{l}\text { +Id_Pertanyaan } \\
\text { +IsiPertanyaan }\end{array}$ \\
\hline & & $\begin{array}{l}\text { +GetDataPertanyaan } 0 \\
\text { + TambahDataPertanyaan } 0 \\
\text { +EditDataPertanyaan0 }\end{array}$ \\
\hline & & $\begin{array}{l}\text { + HapusDataPertanyaan() } \\
\text { +Validasi0 }\end{array}$ \\
\hline
\end{tabular}

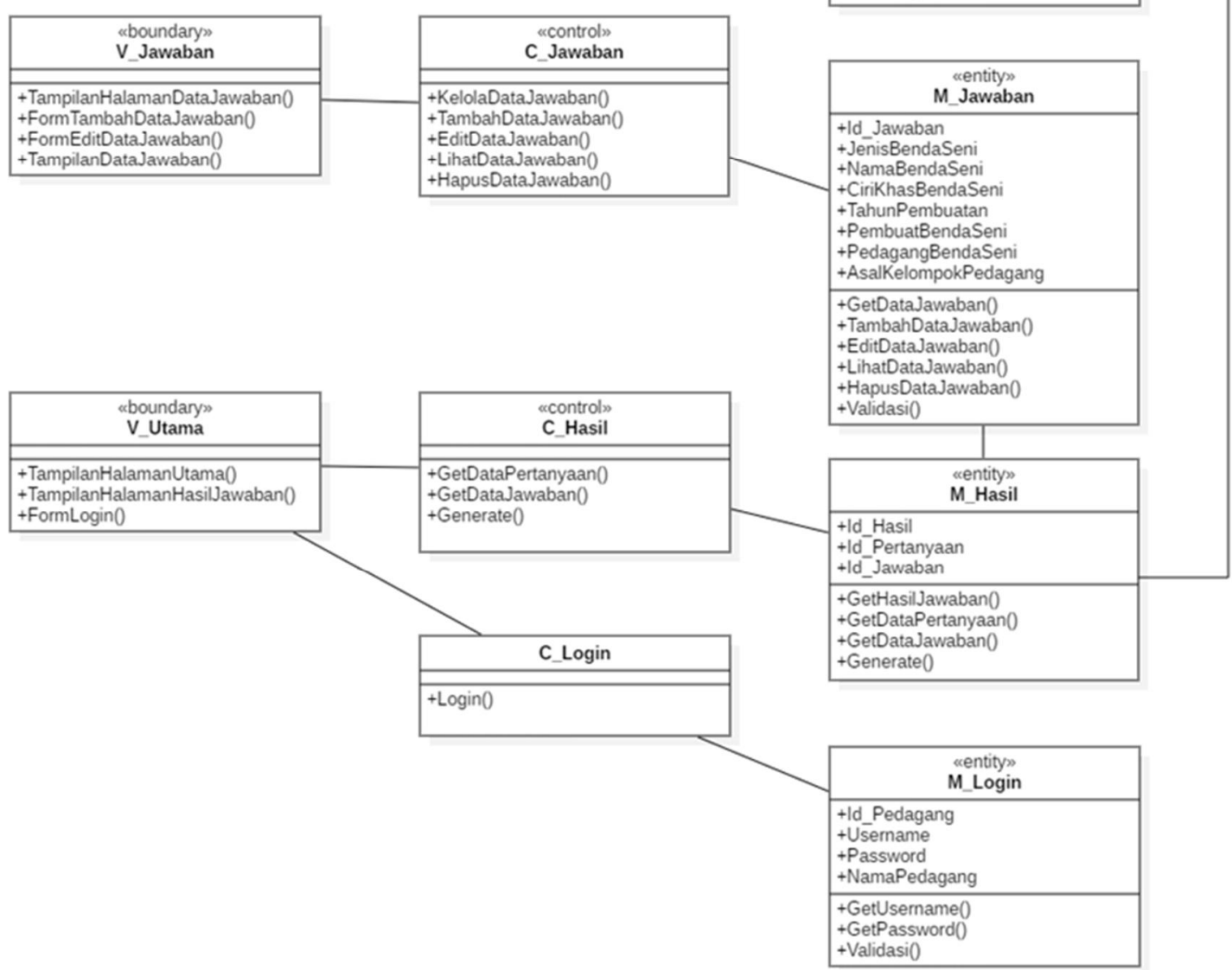

Gambar 4. Class Diagram Question Answering System E-Marketplace Sigertengah

\section{Sprint 4: Sequence Diagram}

Sequence Diagram Cari Jawaban merupakan serangkaian langkah yang berurutan dari proses Cari Jawaban. Adapun rangkaian langkah pada Sequence ini yaitu Pengguna membuka Question Answering System E-Marketplace Sigertengah, kemudian Pengguna memasukkan pertanyaan terkait benda seni pada halaman utama dan klik Generate, melalui control Hasil kemudian reaksi Sistem mengambil, return data hasil jawaban dan menampilkan data hasil jawaban dari model Hasil yang telah dicocokkan kepada Pengguna. Sequence Diagram Cari Jawaban dapat dilihat pada Gambar 5. 


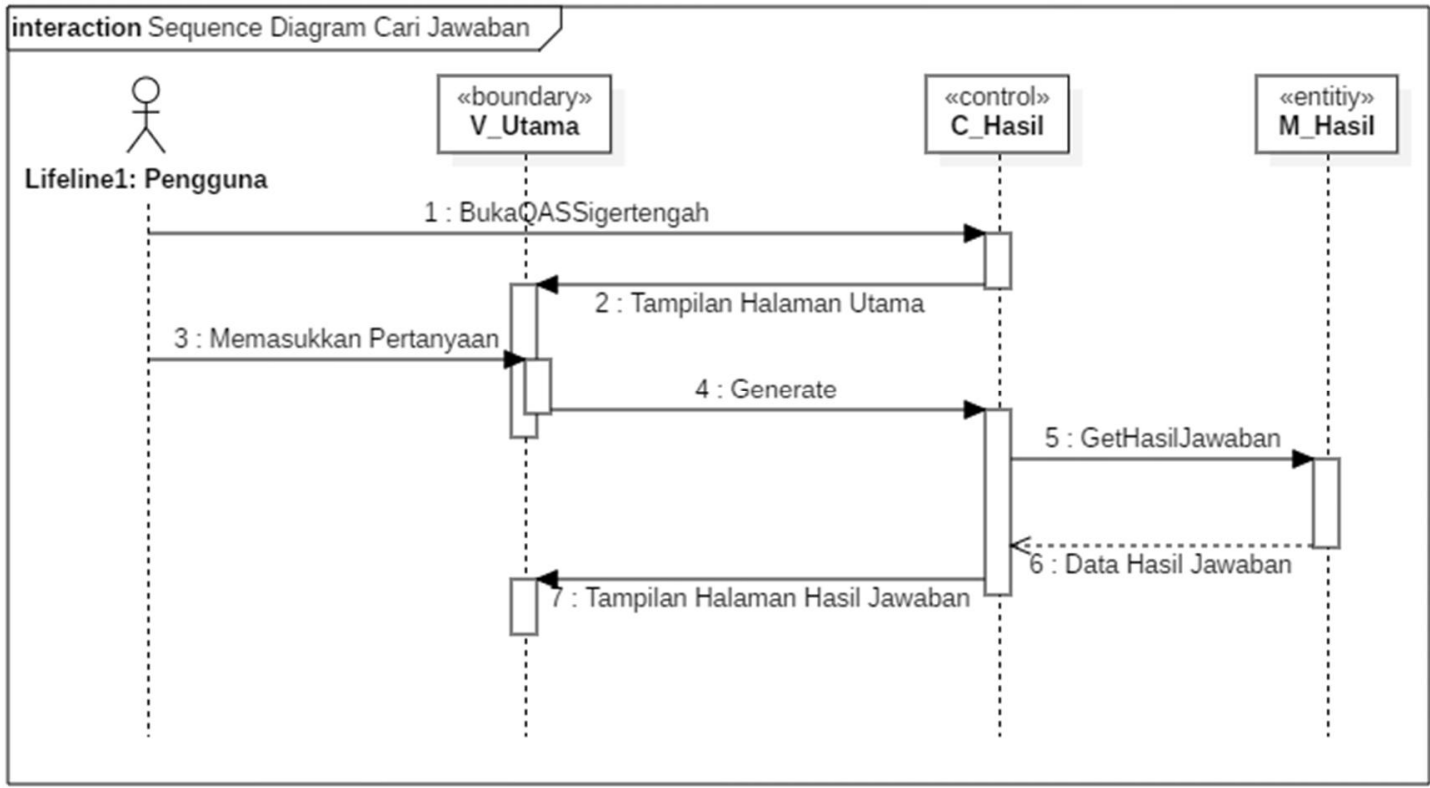

Gambar 5. Sequence Diagram Cari Jawaban

5. Sprint 5: Rancangan Database

d. Kanban Board

Pada tahapan ini menguraikan dan memetakan daftar pekerjaan yang digambarkan dengan tiga fase Kanban Board dengan memvisualisasikan, membatasi pekerjaan yang berjalan dan sesuai dengan alur kerja berfokus pada waktu pengerjaan di dalam pengembangan Question Answering System E-Marketplace Sigertengah dari awal sampai akhir. Adapun Kanban Board fase terakhir dapat dilihat pada Gambar 6.

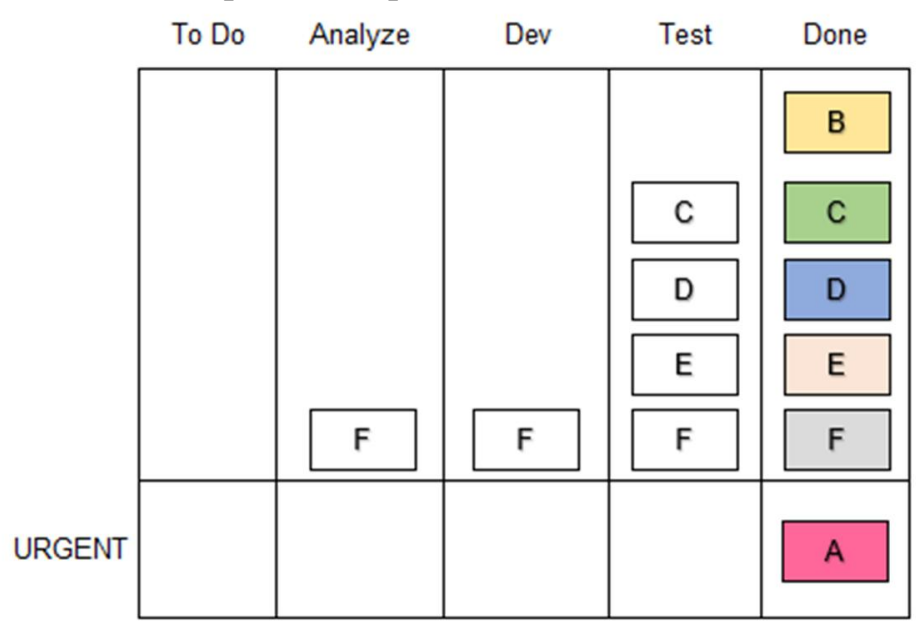

Gambar 6. Kanban Board

Herdian, [Perancangan Question Answering System E-Marketplace Sigertengah Menggunakan Metode Scrumban (Studi Kasus: Kelompok Pedagang Sigertengah)] 


\section{HASIL DAN PEMBAHASAN}

Penelitian ini menghasilkan sebuah rancanagan atau Prototype Question Answering System E-Marketplace Sigertengah menggunakan metode Scrumban. Adapun aktor yang terdapat pada sistem ini diantaranya Pedagang, Member, dan Pengunjung. Dengan adanya sistem ini diharapkan mampu menemukan informasi hasil dari pencocokkan antara pertanyaan dan jawaban dimana hal tersebut akan sangat membantu calon pembeli dalam mengeksplorasi benda seni yang akan dibeli.

\subsection{Rancangan Interface}

Rancangan Interface dari Question Answering System E-Marketplace Sigertengah merupakan gambaran tampilan sistem yang bertujuan agar Pengguna dapat mengetahui dan memahami sistem.

a. Halaman utama

Halaman ini merupakan halaman yang dapat digunakan Pengguna untuk mencari jawaban terkait informasi benda seni.

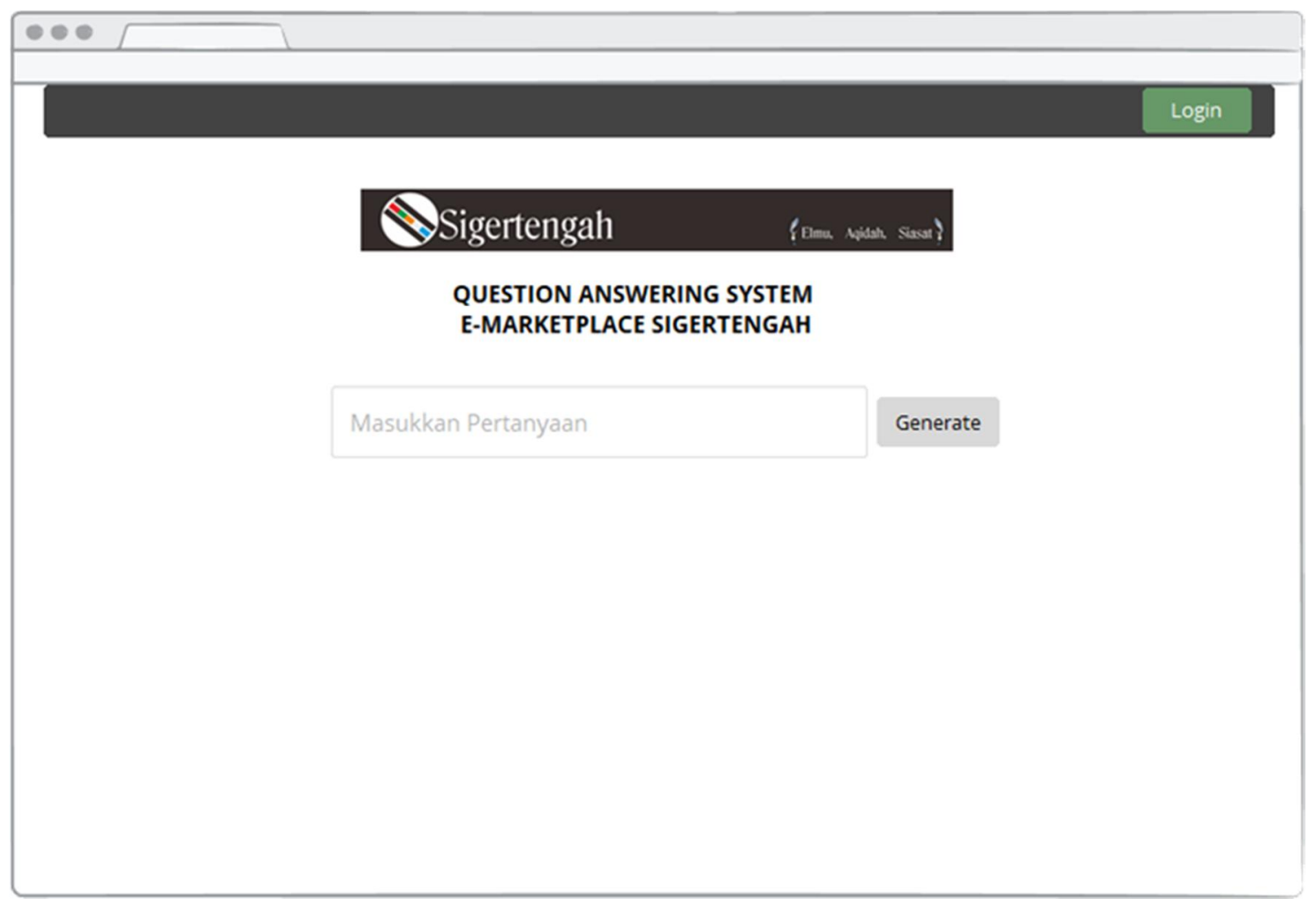

Gambar 7. Halaman Utama Question Answering System E-Marketplace Sigertengah

b. Halaman Login

Halaman ini merupakan halaman yang dapat digunakan Pedagang untuk dapat masuk kedalam menu yang ada pada Back-End Question Answering System E-Marketplace Sigertengah. 


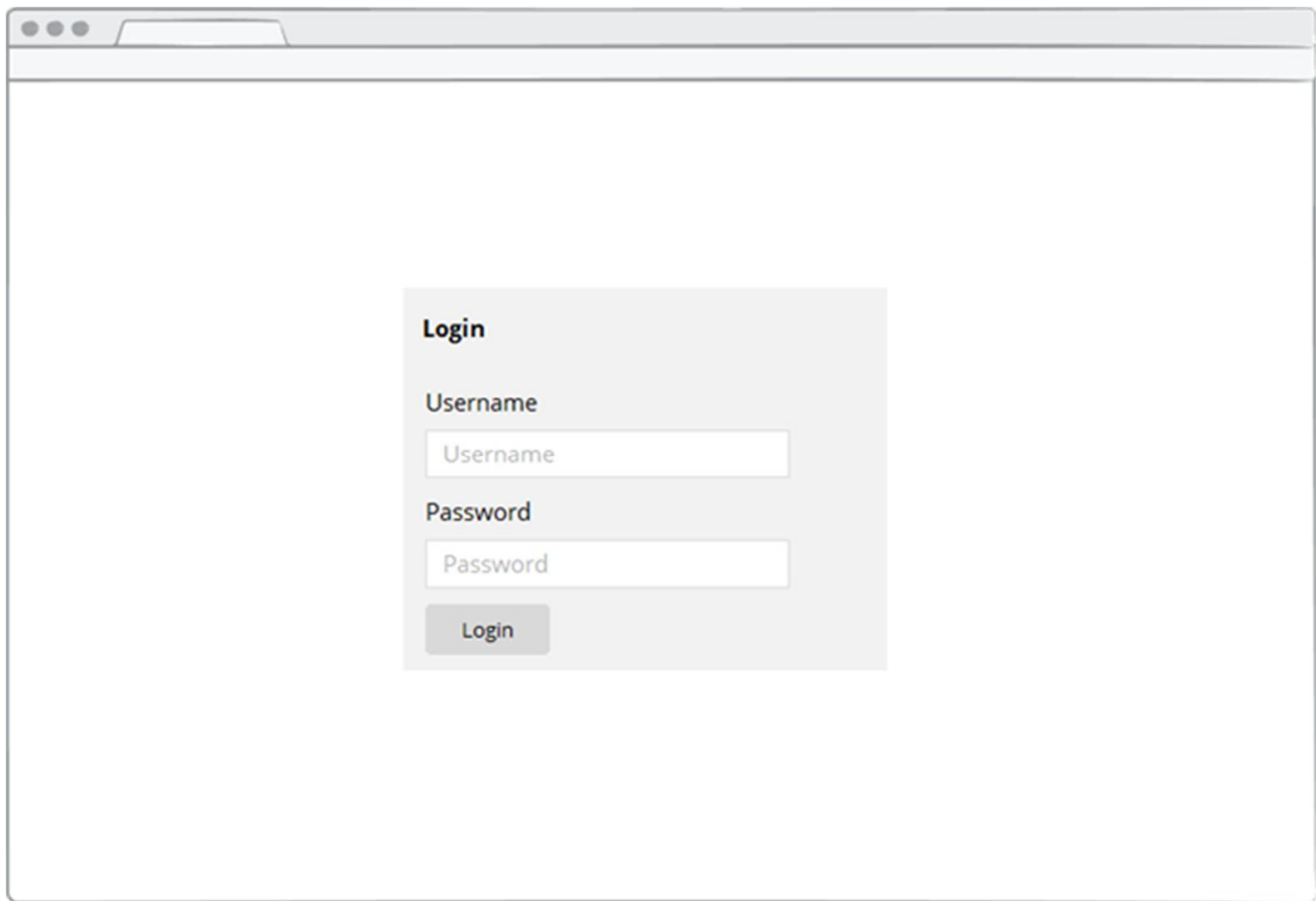

Gambar 8. Halaman Login

c. Halaman Back-End

Halaman ini merupakan halaman yang dapat dilihat oleh Pedagang, terdapat menu Kelola Data Pertanyaan dan Kelola Data Jawaban.

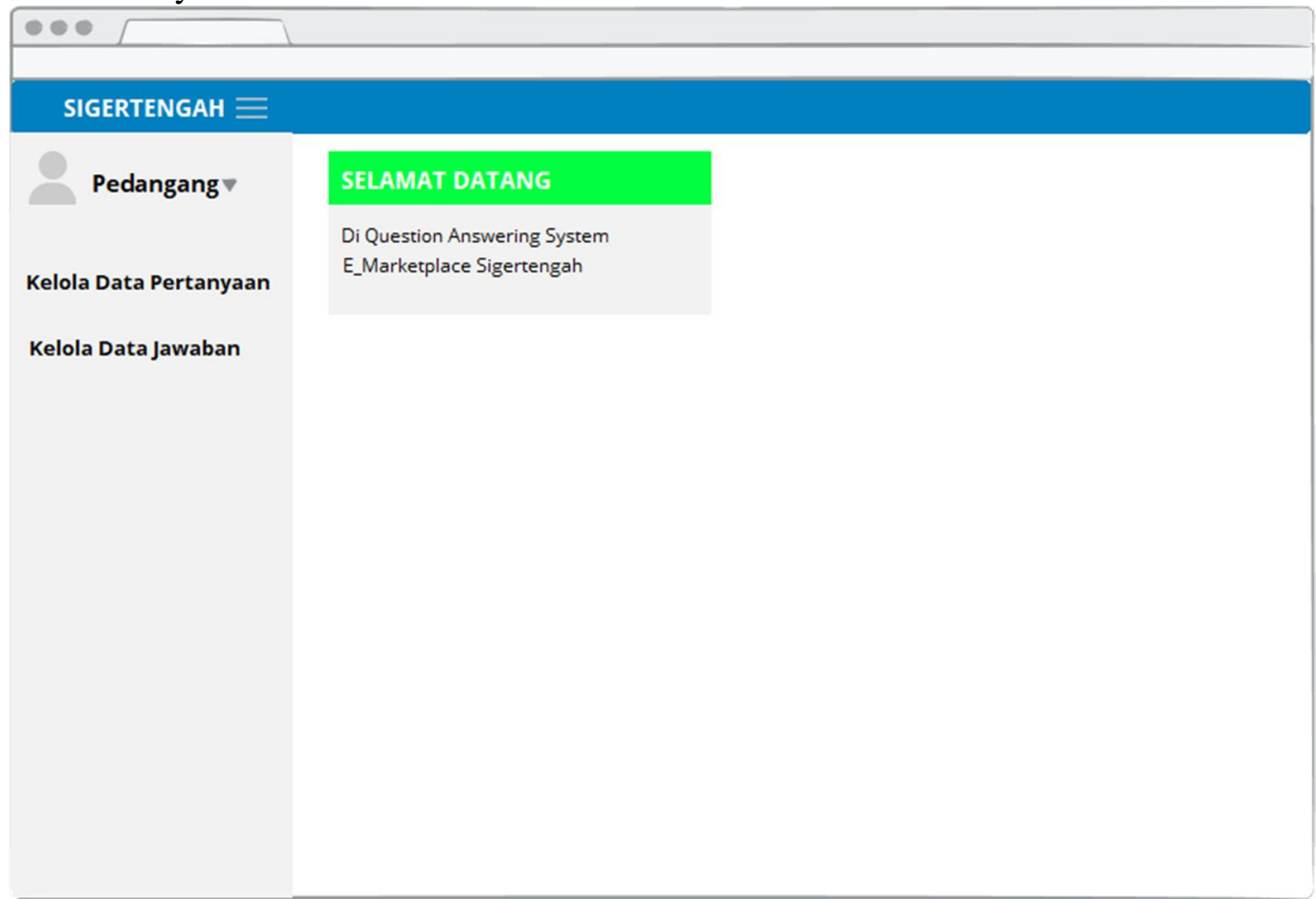

Gambar 9. Halaman Back-End

Herdian, [Perancangan Question Answering System E-Marketplace Sigertengah Menggunakan Metode Scrumban (Studi Kasus: Kelompok Pedagang Sigertengah)] 
d. Halaman hasil jawaban

Halaman ini merupakan halaman yang dapat digunakan Pengguna untuk melihat hasil jawaban dari pertanyaan yang diajukan.

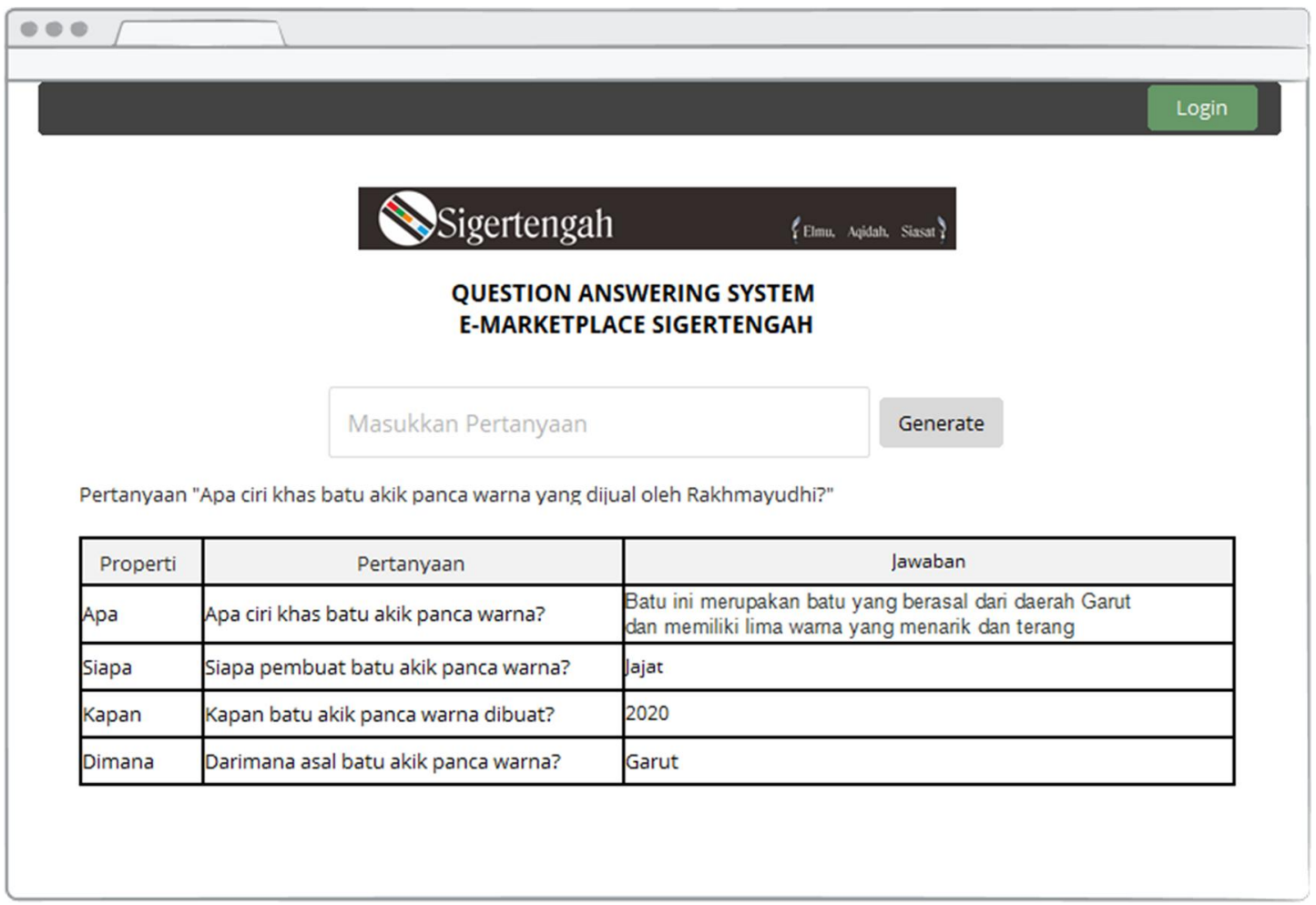

Gambar 10. Halaman Hasil Jawaban

\subsection{Rencana Implementasi Sistem}

Rencana implementasi sistem yang dilakukan dalam menerapkan Question Answering System E-Marketplace Sigertengah yaitu dengan berbasis web. Dimana sistem ini merupakan suatu sistem yang ditujukan untuk dipergunakan oleh kelompok pedagang Sigertengah di $E$ Marketplace benda seni dalam menjalankan pelayanan terhadap konsumen atau calon pembeli mengenai informasi secara detail terkait benda seni yang akan dibeli.

Tabel 3. Rencana implementasi fitur Question Answering System E-Marketplace Sigertengah

\begin{tabular}{|c|l|l|}
\hline No & \multicolumn{1}{|c|}{ Fitur } & \multicolumn{1}{|c|}{ Deskripsi } \\
\hline 1 & Login & $\begin{array}{l}\text { Fitur ini digunakan untuk masuk kedalam sistem } \\
\text { (tampilan back-end) }\end{array}$ \\
\hline 2 & Cari Jawaban & $\begin{array}{l}\text { Fitur ini digunakan untuk mencari hasil jawaban dari } \\
\text { pencocokkan (pattern matching) antara data pertanyaan } \\
\text { dan data jawaban }\end{array}$ \\
\hline 3 & Tambah Data Pertanyaan & Fitur ini digunakan untuk menambahkan data pertanyaan \\
\hline 4 & Edit Data Pertanyaan & $\begin{array}{l}\text { Fitur ini digunakan untuk memperbaharui data } \\
\text { pertanyaan }\end{array}$ \\
\hline 5 & Lihat Data Pertanyaan & Fitur ini digunakan untuk melihat data pertanyaan \\
\hline 6 & Hapus Data Pertanyaan & Fitur ini digunakan untuk menghapus data pertanyaan \\
\hline
\end{tabular}

Herdian, [Perancangan Question Answering System E-Marketplace Sigertengah Menggunakan Metode Scrumban (Studi Kasus: Kelompok Pedagang Sigertengah)] 


\begin{tabular}{|c|l|l|}
\hline No & \multicolumn{1}{|c|}{ Fitur } & \multicolumn{1}{c|}{ Deskripsi } \\
\hline 7 & Tambah Data Jawaban & Fitur ini digunakan untuk menambahkan data jawaban \\
\hline 8 & Edit Data Jawaban & Fitur ini digunakan untuk memperbaharui data jawaban \\
\hline 9 & Lihat Data Data Jawaban & Fitur ini digunakan untuk melihat data jawaban \\
\hline 10 & Hapus Data Jawaban & Fitur ini digunakan untuk menghapus data jawaban \\
\hline
\end{tabular}

Adapun skema jaringan internet yang digunakan pada Question Answering System EMarketplace Sigertengah dapat dilihat pada Gambar

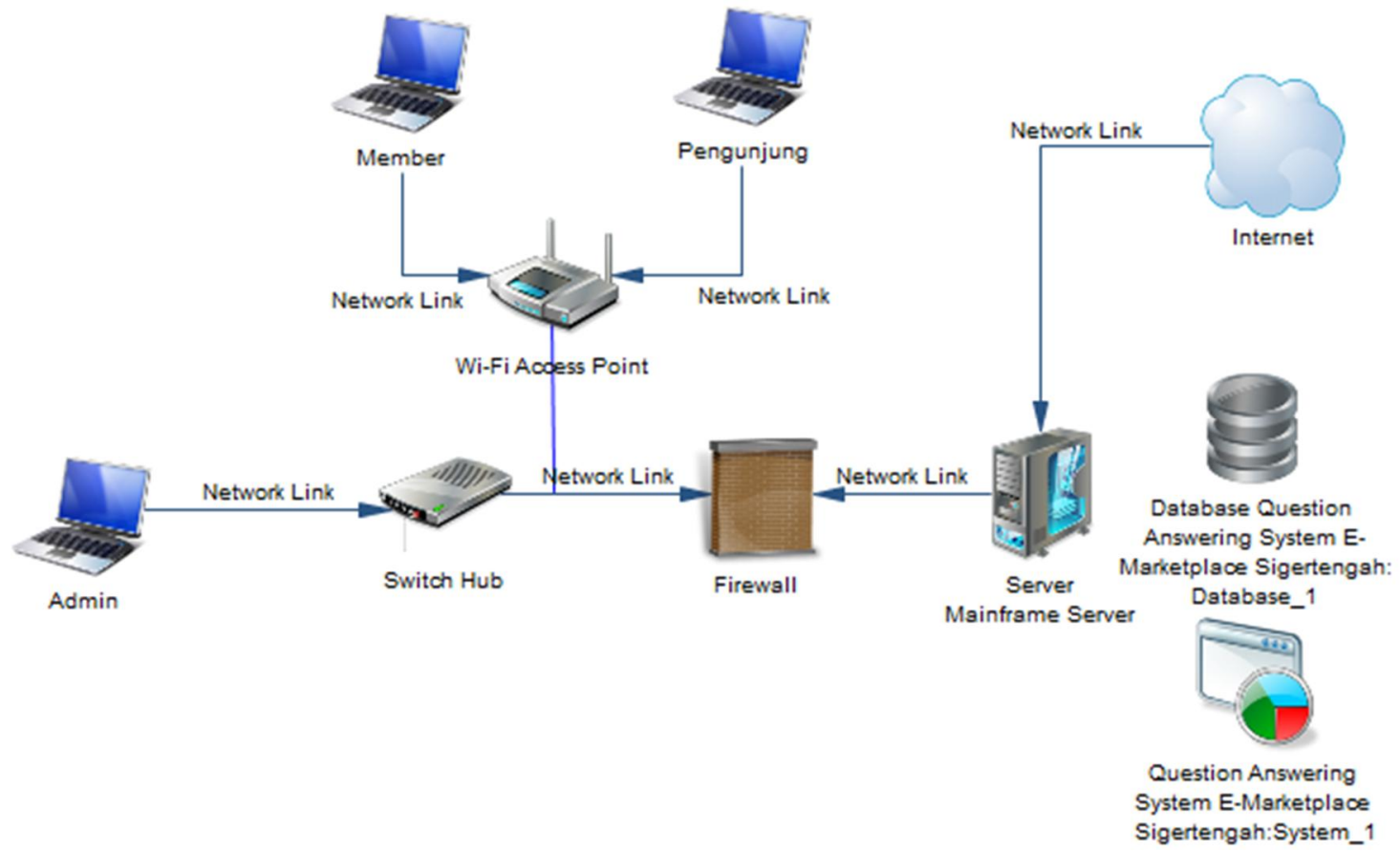

Gambar 11. Skema Jaringan Question Answering System E-Marketplace Sigertengah

\section{KESIMPULAN}

diantaranya:

Terdapat beberapa kesimpulan yang dapat diberikan berdasarkan penelitian ini

1. Rancangan Question Answering System E-Marketplace Sigertengah ini dapat menjadi gambaran dalam pengembangan E-Marketplace Sigertengah.

2. Penerapan metode Scrumban membantu dalam perancangan Question Answering System E-Marketplce Sigertengah dari segi waktu penyelesaian pekerjaan dan memetakan fokus pekerjaan yang harus segera dikerjakan.

3. Perencanaan implementasi Question Answering System E-Marketplace Sigertengah ini terdapat beberapa aspek diantaranya aspek Pengguna, perangkat lunak, perangkat keras, dan skema jaringan internet.

Herdian, [Perancangan Question Answering System E-Marketplace Sigertengah Menggunakan Metode Scrumban (Studi Kasus: Kelompok Pedagang Sigertengah)] 


\section{SARAN}

Diharapakan agar dapat memperluas ruang lingkup dari segi memasukkan pertanyaan dengan menggunakan fitur seperti speech to text. Juga dapat dikembangkan menjadi berbasis mobile dengan tampilan yang menarik dan sederhana sehingga dapat lebih mempermudah calon Pembeli dalam mencari sebuah informasi terkait benda seni yang ditawarkan di E-Marketplace Sigertengah.

\section{UCAPAN TERIMA KASIH}

Terima kasih yang sebesar-besarnya kepada kelompok pedagang Sigertengah yang telah memperkenankan Penulis untuk mengadakan penelitian dan pihak-pihak yang telah mendukung, sehingga Penulis dapat menyelesaiakan rancangan Question Answering System E-Marketplace Sigertengah menggunakan metode Scrumban.

\section{DAFTAR PUSTAKA}

[1] C. A. Herdian. 2019, "Sistem Informasi E-Marketplace Benda Seni pada Kelompok Pedagang Sigertengah,” Global, Vol. VI, No. 2, pp. 48-58.

[2] N. Halimahturrafiah. 2019, "Peran Sistem Informasi Manajemen Dalam Pendidikan," Vol. 16, doi: 10.31227/osf.io/5ef7a.

[3] Rakhmayudhi and W. Suwarningsih. 2020, "Template Pattern for Simple Question Transformation,” 2020 3rd Int. Conf. Comput. Informatics Eng. IC2IE pp. 188-193, doi: 10.1109/IC2IE50715.2020.9274666.

[4] A. Dewi and B. Setiaji. 2014, "Pemanfaatan Sentence-Similarity Measurement Untuk Proses Pencarian Pola pada Chatbot Berbasis Pattern-Matching,” Semin. Nas. Teknol. Inf. dan Multimed, pp. 39-44.

[5] M. Alqudah and R. Razali. 2018, "An Empirical Study of Scrumban Formation Based On The Selection of Scrum and Kanban Practices," Int. J. Adv. Sci. Eng. Inf. Technol., Vol. 8, No. 6, pp. 2315-2322, doi: 10.18517/ijaseit.8.6.6566.

[6] E. al. Sibarani. 2017, “Panduan Scrum,” Imp. J. Interdiscip. Res., Vol. 2, No. 12, pp. 293-298, [Online]. Available: https://www.scrumguides.org/docs/scrumguide/v2017/2017-Scrum-GuideIndonesian.pdf.

[7] K. Schwaber and J. Sutherland. 2015, "Scrum Guide V7,” No. November, pp. 133-152.

[8] N. Faizah, N. Santoso, and A. A. Soebroto. 2019, "Pengembangan Sistem Aplikasi Manajemen Proyek Menggunakan Kanban Framework," J. Pengemb. Teknol. Inf. dan Ilmu Komput., Vol. 3, No. 10, pp. 9747-9754. 
[9] D. Dewantoro. 2020, "Implementasi Metodologi Kanban Dalam Pembuatan Aplikasi ECommerce Pertanian Dengan Pendekatan Zachman Framework," Vol. 3, No. 28.

[10] A. Reddy. 2016, The Scrumban Revolution, No. 1.

[11] A. J. Paul and S. K. Rahman. 2018, "Study On Agile Management in Construction Project Using Scrumban Methodology,” Int. Res. J. Eng. Technol., Vol. 5, No. 11, pp. 774-777, [Online]. Available: www.irjet.net. 